\title{
ERRATUM
}

\section{Weight maintenance and additional weight loss with liraglutide after low-calorie-diet-induced weight loss: The SCALE Maintenance randomized study}

TA Wadden, P Hollander, S Klein, K Niswender, V Woo, PM Hale and L Aronne on behalf of the NN8022-1923 Investigators

International Journal of Obesity (2015) 39, 187; doi:10.1038/ijo.2014.88; published online 14 October 2014

Correction to: International Journal of Obesity 2013; 37: 1443-1451; doi:10.1038/ijo.2013.120

Further to erratum: IJO.2013.148 there is also an error on page 1448, Table 3, as outlined below:

- In column 1, the second subheading under 'Co-primary end points' should read 'Proportion maintaining $\geqslant 5 \%$ run-in weight loss' (not $>5 \%$ ).
- In column 1, the third subheading under 'Co-primary end points' should read 'Proportion with $\geqslant 5 \%$ weight loss' (not $>5 \%$ ).

The publisher apologises for this error. 